FLINT IMPLEMENTS AND FOSSIL REMAINS FROM A SULPHUR SPRING AT AFTON, INDIAN TERRITORY

\author{
By W. H. HOLMES
}

\title{
INTRODUCTION
}

During the summer of I9OI the attention of the Smithsonian Institution was called to a new site yielding fossil remains of the mastodon and mammoth, and numerous flint implements in close association with them. The information was furnished by $\mathrm{Dr}$ R. H. Harper, of Afton, Indian Territory, who, on making a superficial examination of the site, became convinced that the phenomena were of much scientific interest. Through his solicitation the National Museum took the matter up, and Mr F. A. Lucas, of the division of osteology, sent his assistant, $\mathrm{Mr}$ A. Stewart, to make investigations, the particular object being to procure a complete skeleton of mammoth or mastodon for the Buffalo Exposition: but $\mathrm{Mr}$ Stewart found that the remains of fossil animals at Afton were dissociated and fragmentary, and the investigation was abandoned after slight excavations had been made.

Owing to the report that relics of human handiwork were found associated with the fossil remains, I resolved to visit Afton and make investigations. Setting out for the west on September 26, I stopped over a couple of days at Saint Louis to visit the fossil mastodon beds at Kimmswick, twenty-five miles south of the city and, in company with $\mathrm{Mr} \mathrm{C}$. W. Beehler and $\mathrm{Mr}$ T. D. Townsend, who are interested in the property and engaged in its exploration, spent a most instructive day at the site. The question of the association of human remains with those of the mammoth and mastodon has also been raised at this place, but up to 
the present time the evidence collected is not sufficiently strong to be at all conclusive. It is believed that the bones found which so closely resemble the humerus of man may be portions of the fibulæ of young mastodons, and that the flint implements, which are plentiful on the surface of the site, may have been only recently associated with the fossil remains. At any rate, it seems wise to suspend judgment in the case until more critical and exhaustive studies have been made. Resolving to return at an early date and make fuller examinations, I hastened on to Indian Territory.

\section{THE SPRING AT AFTON}

The village of Afton, Indian Territory, a station on the Saint Louis and San Francisco Railway, is situated in the midst of a plain which occupies the angle between Arkansas river and its northern tributary, Neosho or Grand river. The former stream enters the Territory from Kansas on the north, flowing southeastward and passing into Arkansas at Fort Smith, while the Grand rises in southeastern Kansas and southwestern Missouri and flows southward across the plains, joining the Arkansas in Cherokee reservation, forty-five miles south of Afton. Forests grow along the more rugged bluffs and on the occasional low hills, but the general region is almost treeless. The country is now very well settled, and farming and grazing are carried on with success.

The geologic formations underlying the immediate region of Afton appear to be of Silurian age, the strata being approximately horizontal, but they are much obscured by superficial deposits save in the banks of the rivers and their larger tributaries.

The springs, with which the fossil remains and artifacts are associated, are situated in a shallow wash at the very head of one of the lateral branches of Horse creek, a tributary of the Neosho, falling into it from the north. The wash has no water, and probably never carried a stream save in times of heavy rainfall or as a result of the melting of snow in the spring. In summer the 
water from the springs sinks from sight a few hundred yards from the source. The wash, which ramifies in various directions, is in places two hundred feet wide, and has a level floor only slightly depressed beneath the surface of the surrounding prairie. In this flat space the sulphur springs rise, and the water, spreading out, forms a marshy area an acre or more in extent, which is much trampled by cattle when they have access to it, as it doubtless was at an earlier date by herds of buffalo and possibly by greater mammals that went before them. The surface is soft and spongy, sinking beneath the feet; and, in approaching the spring basin, it was necessary to lay down boards to insure a footing.

The basin of the principal one of the three springs forming the group was boxed in with rough boards, a second and very weak spring occurring some forty feet to the west, and a third, a little stronger, in a side wash perhaps a hundred and fifty yards to the northeast. The water rises in the principal spring so rapidly that it requires quite steady dipping on the part of a single workman to keep the flow down. It is quite clear and so slightly impregnated with sulphur that it is used by the people of the vicinity for drinking purposes. The flow is steady, not changing winter or summer, a fact which indicates the great depth of the source - probably in the reservoirs from which the artesian water of the general region is obtained.

\section{TRADITIONS REGARDING THE SPRING}

In the neighborhood the spring has the reputation of possessing unusual medicinal qualities, and it is said that the aborigines of the region were formerly in the habit of gathering from all directions and camping near it for the purpose of drinking the water. This tradition refers, apparently, to the Cherokee; but since these people are recent arrivals in the west and appear to have no definite knowledge of the matter, I was inclined to believe that the tradition related to the tribes who preceded them 
in the region, and that the qualities of the spring were not medi. cinal, as we understand the term, but magical attributes such as are commonly associated with sources of water supply by primitive peoples. This point will receive attention later. Careful search in the vicinity of the springs failed to bring to light even the most meager traces of aboriginal occupancy.

\section{FIRST CLEARING OUT OF THE SPRING}

At an early date a barrel was set into the soft ground to receive and retain the water, and about fourteen years ago this was superseded by a strong box, but as the boards were sharpened and driven down the deposit of flints in the spring was not seriously disturbed. Later a new box was set inside of the old one, and in cleaning out the reservoir many implements and bones were found. It is stated that at that time a bushel or more of the flints were thrown out and distributed among various persons. ${ }^{1}$ It is much to be regretted that none of these have been preserved. Subsequent cleanings out yielded additional implements, and in the summer of I9OI, Dr Harper obtained about one hundred and fifty specimens and some fossil teeth, and these have been presented to the Smithsonian Institution. In June, I90I, Mr Stewart visited the place and made the slight excavations already referred to, but did not penetrate deep enough to discover the deposit of implements.

\section{FINAL EXAMINATIONS?}

Having procured workmen and supplied myself with all necessary tools and appliances, $I$ built a long trough to carry the water well away from the spring and at once began the work of bailing out the basin. The box was about four feet square and made of

\footnotetext{
${ }^{1}$ It should be noted that the stories relating to this period of the history of the spring vary considerably.

${ }^{2}$ My thanks are due to Dr Dawson, owner of the property, for the privilege of making excavations. I must add also that most valuable aid was given in the work of excavation by Mr DeLancey Gill, of the Bureau of American Ethnology, who accompanied me on the trip.
} 
heavy boards held in place by timbers on the inside. About four feet from the surface of the ground silt was encountered, then sand and fine gravel, and with these latter came up teeth of small mammals and an occasional mammoth tooth, also some flint implements, the number increasing as descent was made. When comparatively firm gravels were reached, at five or five and onehalf feet, the teeth and flints were found in great abundance, and the shovel, which was now brought into use, when inserted beneath the lower ends of the boards at the northern side, came out half filled with the handsome blue and white spearpoints and knives, and along with these were bones of horses, deer, buffalo, and wolves. A little further excavation beneath the northern margin of the box brought to light the head of a buffalo, and antlers and bones of two or more deer. With the deposit were also a number of implements made of deer antler which resemble very closely the hammers and pressure-flaking implements used by the tribes of the region in shaping flint.

The spring box, now being without sufficient support on the inside, collapsed, letting in the beds of soft muck and sand. It thus became necessary to make excavations outside of the spring basin sufficiently extensive to enable the workmen to clear away the wrecked box and prevent further caving in. Removing the superficial muck, which was about two feet in thickness, from a considerable area, it was found that it rested on the surface of a bed of compact and extremely fine sand, which was quite firm save about the spring box where it had been disturbed by the original cleaning out of the spring and by the slight excavations of $\mathrm{Mr}$ Stewart. In the muck nothing excepting a few fragments of bones of buffalo were encountered, and there were only occasional specimens in the sand. The discovery of a large spearpoint in the sand at a depth of three feet from the surface of the ground was a surprise. This was, perhaps, three or four feet horizontally from the northern side of the box as it originally stood. Since this locality had been undoubtedly a resort of the 
buffalo for a long period, instances must now and then have occurred of the death of wounded animals whose bodies contained the missiles shot into them, and in this way it is easy to account for the finding of stray spearpoints, and these naturally would occur at depths in the formations as great as were reached by the bones of the animals themselves.

Half a day was consumed in getting rid of the wrecked box and clearing out the muck and water. A pump was used to remove the water, and this work was kept up all night to prevent flooding; but on the second night the pump failed and the whole place was soon under water, causing much delay. Reaching finally the level of the flint deposit in the spring, we began to encounter the implements and took out a hundred or more, besides additional bones of the buffalo, elk, deer, and wolf. The finding of the flints was under such conditions of water encroachment and deep shadow that it was not possible to obtain photographs; but this seemed of little consequence, as the specimens did not occur in any particular order. They were piled together as if deposited, mainly at least, at one time, in the mouth of the spring. The main body of them had descended to a depth of from four to seven feet, and with the exception of a few stray pieces, such as those already referred to, they were included in a space not more than three feet in diameter. In this cluster also were most of the modern bones as well as many of the ancient remains. At seven feet in depth there were no more flints, but occasional teeth of the horse occurred along with the great teeth of the mammoth. Work was continued long enough to make sure that there were no more flints, and some time was spent in adding to the collection of fossil teeth. Before the filling of the excavation, a new box, four feet square and seven feet deep, was set in the spring, and we had the pleasure of seeing the bubbling water rise in it as the work went on.

AM. ANTH. N. S., $4-8$. 


\section{THE FORMATIONS}

Other excavations were made at various points with the view of determining the nature and extent of the formations. After our departure from Afton, Dr Harper, working under my instructions, sunk three pits - one north of the spring, twenty feet long and thirteen feet deep, which practically connected with the original excavation; a second, eleven feet deep, twenty-five feet west of the spring; and a third, nine feet deep, south of the spring twenty-five feet away.

The section (fig. 5) shows the geological formations, together with the position and relations of the various finds of bones and

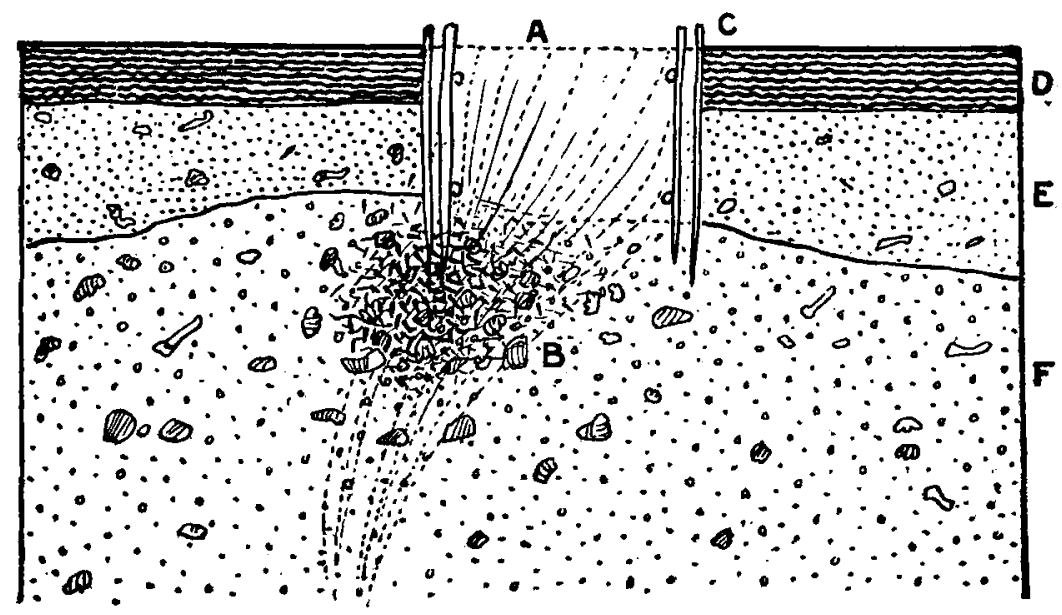

FIG. 5-Section of the spring deposit and geological formations. $A$, spring; $B$, spring deposit of

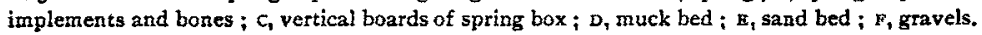

implements. It is clear that the deposits of sand and gravel are not local, pertaining exclusively to the spring or even to the spring group, but that they occupy a considerable area, as if deposited in a large body of water or by a river of considerable size. Our lowest excavation was only thirteen feet in depth, but the sounding rod indicated at least sixteen feet of finely comminuted deposits. There is, however, considerable irregularity in the thickness of the formations examined. The muck bed, which is 
two or three feet deep in the vicinity of the springs, gradually changes to sandy loam as the margins of the wash are reached. This muck represents merely the depth of disturbance by the feet of cattle and the consequent interference with free drainage of the water, the growth of marsh vegetation being the result of the constantly moist condition of the trampled area. The bed of sand beneath the muck has an approximately level upper surface, but is not of uniform depth. It is three or four feet thick at the spring and ten or more twenty feet away. In the upper part it is extremely fine in texture, but lower there are layers of fine gravel, and Dr Harper reports, as a result of his examinations, that the sand and gravel are distinctly bedded as if laid down in water. The gravel consists almost wholly of chert, and in the main is finely comminuted but not uniformly water-worn, a large part being angular or subangular. Many of the pebbles, and even some of the fossil teeth, are coated completely with sulphide of iron, giving the effect of gilding.

\section{FOSSIL REMAINS}

Our examinations developed the fact that the fossil remains were much more numerous in the spring and near it than elsewhere. There were more mammoth and mastodon teeth within a radius of three feet from the spring basin and between four and seven feet in depth than in all the other material examined. In this restricted area there were at least one hundred mastodon teeth and perhaps twenty mammoth teeth, besides considerable numbers of teeth of fossil bison and horse, as well as the whole deposit of implements and recent bones. In the excavation north of the spring, twenty feet long, four feet wide, and thirteen feet deep, not half a dozen teeth of all varieties were found. In all the excavations outside of the spring the distribution of fossil remains was apparently quite uniform throughout the sand and gravel. Some of the teeth were beautifully preserved, others were so disintegrated as to fall to pieces on being touched, while 
fragments were common and presented the appearance of attrition from water transportation.

In seeking an explanation of the prevalence of mastodon and mammoth teeth in the spring, several surmises may be made. Possibly, if the spring is very ancient, the great pachyderms mired more frequently in its basin than elsewhere, leaving their bones in the muck. Possibly the spring funnel was a receptacle for such bones as were weathered out of neighboring formations and carried by water or by gravity into the opening; and possibly movements of the soft deposits, on occasions of particular disturbance or strong pressure from beneath, have been toward the points of least resistance at the spring. The finely comminuted materials, the sand and clay, would be carried away by the strong flow of water, and the great teeth and the coarse gravel would remain in the basin. At least one instance was observed of such movement in the deposits near the spring. A year or two previous to my visit to Afton, and during the wet season, a body of liquid and semi-liquid material suddenly broke through the surface of the ground near the spring, like a bursting bubble, leaving a little hillock which is still distinctly visible. Such movements may have occurred from time to time, the direction being horizontal and toward the spring or directly or obliquely upward.

But perhaps the most plausible theory that can be advanced to account for the accumulation of bones in the spring, is that when the place became an object of special attention on the part of the native tribes, such bones as were exposed in the vicinity were gathered and cast in as appropriate offerings to the beings supposed to inhabit it. This suggestion is strengthened by the fact that the ancient bones are more plentiful in exactly the area in which the bones of modern creatures and Indian implements are found. Indeed, it is not improbable, as elsewhere remarked, that the occurrence of these huge bones gave rise to the superstition in the native mind that powerful spirits made this their dwelling-place - that the spring was the doorway to the realm 
beneath. The remains of recent forms were nowhere more than four or five feet in depth, except in the immediate vicinity of the spring funnel where they were deeper and the teeth of a modern horse were, as already stated, found associated with mammoth teeth seven feet deep.

It is clear that in the formations outside of the spring remains of the ancient creatures are quite uniformly distributed, and it appears that everywhere they are fragmental, the bones being separated and broken up as if subjected, at some past period, to vigorous transportation by water or to crushing under the feet of monsters trampling in the muck. In some instances two or more teeth were so related as to show that they had been in place in the jawbone when carried to their present position.

The remains of tusks were also fragmental, and in all cases in a state of disintegration so advanced that only small portions could be saved. The bones are broken with a sharp fracture as if already brittle from decay or silicification when the disturbing agencies were active. In the neighborhood stories are told of the discovery, about the spring, of bones of great size, but the largest piece encountered in our excavations was half of the lower jaw of a mastodon.

The largest mammoth teeth are a lower tooth sixteen inches in length, and an upper tooth eleven inches in length and very massive. Dr Lucas, observing the differences between two specimens (the one being finely and the other coarsely ribbed), expresses the opinion that they may possibly represent two varieties of mammoth - Elephas primigenius and Elephas imperator, the latter species, proposed by Cope, not as yet having been generally accepted.

Associated intimately with the flint implements in the spring were some of the leg.bones of two or three buffalo, four or more deer, one elk, half a dozen wolves, and one or more horses. These were a little more widely distributed than the flints, but were distinctly a spring deposit, and it is not unlikely that their presence also was in part or altogether due to human agency. 
The implements found in the spring had been subjected to so much disturbance before my arrival that the exact nature of the original deposit could not be determined. They were in compact order as if dumped in a body, but much the same result would have followed from the casting in of single specimens or small lots at various times, since all would settle to the deepest possible point in the spring basin, the position and character of which has probably remained unchanged $f_{\phi r}$ a long period. It is impossible to say whether or not the native tribes ever took the trouble to excavate the basin, either for convenience in using the water, to increase the flow in dry seasons, or to facilitate the introduction of the implements; but if the objects deposited were, as we suppose, in the nature of offerings, the spring was a sacred place and no one would venture to disturb it under any circumstances.

It was noted that the remains of buffalo, deer, and wolf were intermingled with the implements and that they were not associated as though the animals had died on the spot, but rather as if the separate bones or dismembered parts of the creatures had been thrown in with the implements. I am inclined to the view that they were cast in as offerings, since there seemed to be a very large and disproportionate number of bones of one kind; for example, not fewer than twenty or thirty of the large, straight legbones of the deer were associated directly with the flints.

If statements coming from apparently reliable sources be correct, more than half the deposit of implements had been removed before my arrival. I obtained altogether, counting fragments and partially shaped pieces, upward of eight hundred specimens, not quite half a bushel; so that there must have been at least a bushel (some say a barrel) of implements in the original deposit, the number reaching somewhere between fifteen hundred and two thousand. They include arrowheads, spearpoints, knives and unspecialized blades, besides some roughed-out forms, and fragments. All were shaped by flaking, and the work is for the greater 

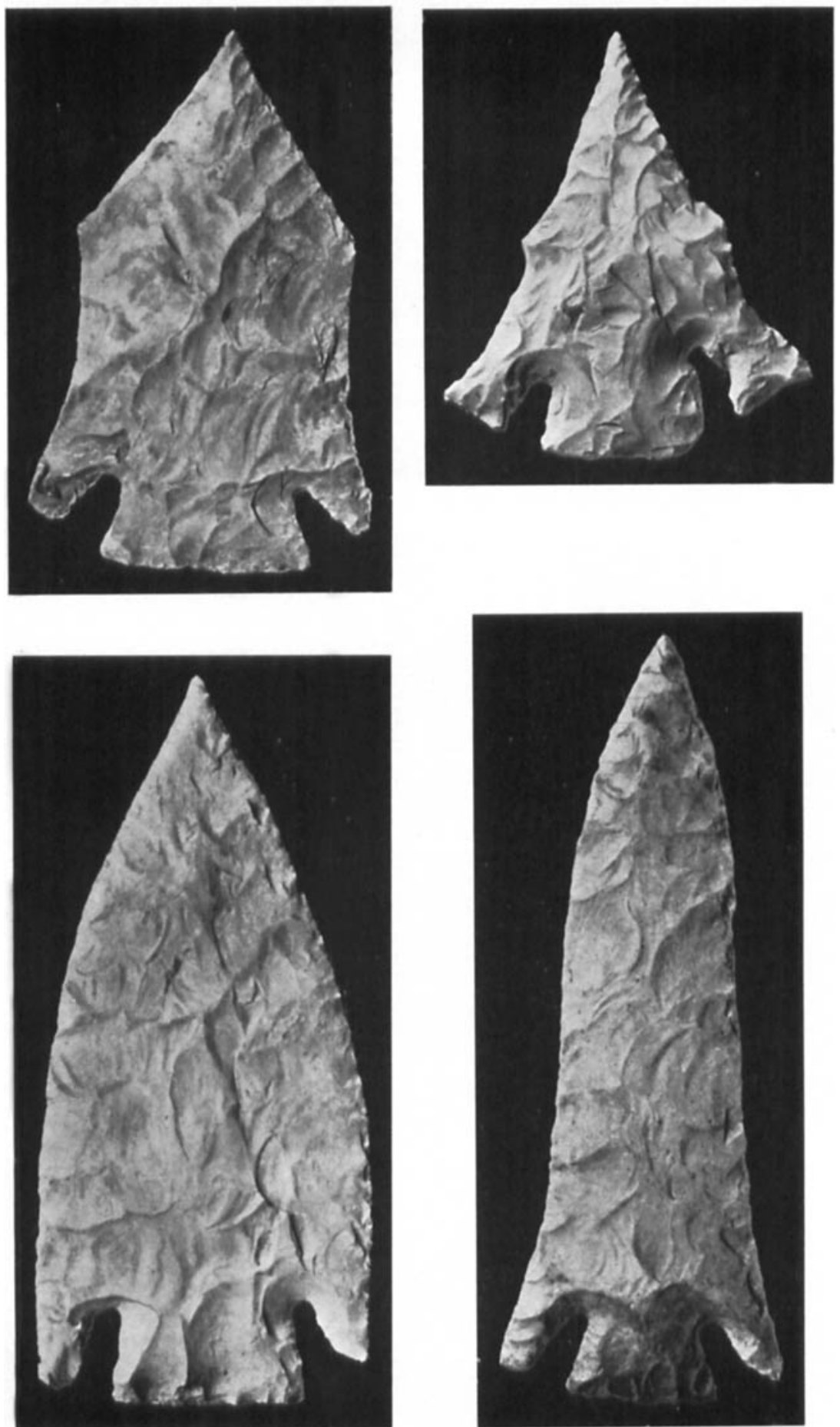

part exceedingly well done. The finished forms appear to be such as would be appropriate to the buffalo hunter equipped for the chase. The spear was, I believe, the main reliance of the Great Plains hunter; but bow and arrow were also in general use, especially for the smaller varieties of game. To pierce successfully the tough hide of the buffalo and penetrate to a vital part, the projectile point had to be thin, long, sharp-edged, and incisive, and the sulphur spring has furnished many perfect specimens of such (plate XI). Our museum collections contain nothing comparable with them, and, excepting such as were probably broken by our excavating tools, all are in perfect condition, as if just from the finishing shop. It is a noteworthy fact that a large number of the spearpoints, as well as knives, had been freshly sharpened when the deposit was made, the old discolored surface being easily distinguished from the more recent chipping (plate XII).

The knife also, of which there are many specimens, was of prime importance to the hunter. The thin blades are from three to six inches in length, from one inch to four inches in width, and show various stages of specialization and wear. Many are, apparently, freshly made leaf-shaped blades, while others have been sharpened and resharpened on one side so as to be scarcely more than half the original width (plate $\mathrm{xI}, b, c$ ). One end of the blade is in all cases wider than the other, and, taking the narrow end as the point of the implement, the sharpening is such as to indicate a right-handed use in nearly all cases.

The chert of which the implements are made is of excellent quality; is white and bluish-gray in a majority of cases, but some specimens are quite dark. It is not of the variety found so plentifully in the quarries of the region about Afton, but is of finer grain. The quarries four miles south of the village, as well as those on the Peoria reservation, twenty-five miles to the northeast, furnish a coarser material, generally somewhat yellowish in color. It is manifest that the flint is nearly all from a single quarry or from a group of sites yielding identical material, and 
there is no doubt that these quarries will be found in good time and not far distant from the Afton springs. A very few pieces are of other varieties of flint, such as are sometimes found scattered over the surface of the country, and some of these may have been brought in from distant points.

One of the most striking features of these implements is that many of them show distinct evidences of recent reshaping. The old surfaces are quite dark, while the new flaking exposes the clean white material. Many arrowheads and spearpoints have been retrimmed, some slightly, others over a large part of the surface; while the knives have been carefully sharpened along one edge (plate XII, $a$ ). Strangely enough, there were many frag. ments and chips of chert scattered through the spring deposits, as if work had been done on the spot or near at hand and the flakage thrown in along with the shaped objects. Traces of what appeared to be arrowshafts of reed were also found.

\section{BONE AND ANTLER IMPLEMENTS}

The bone implements were not at first recognized as such, and probably many were thrown away, being taken for mere fragments of bone. There are three varieties of these objects two made of antler and the other from leg-bones of deer and birds. The most numerous are from the heavy end of the antler, and the length varies from four to seven inches. The base retains its natural form and the other end is slightly rounded off. These objects are of the type known as flint-flakers in the Middle-West, and were probably supplied with handles fastened about the middle portion, making them available for roughing-out the flint blades by percussion.

A second form is such as would be produced by dividing longitudinally the implement described above and rounding down the ends and edges. They were associated with the flint knives, and in such an intimate way as to lead to the supposition that they may have served as handles. They could have been set 



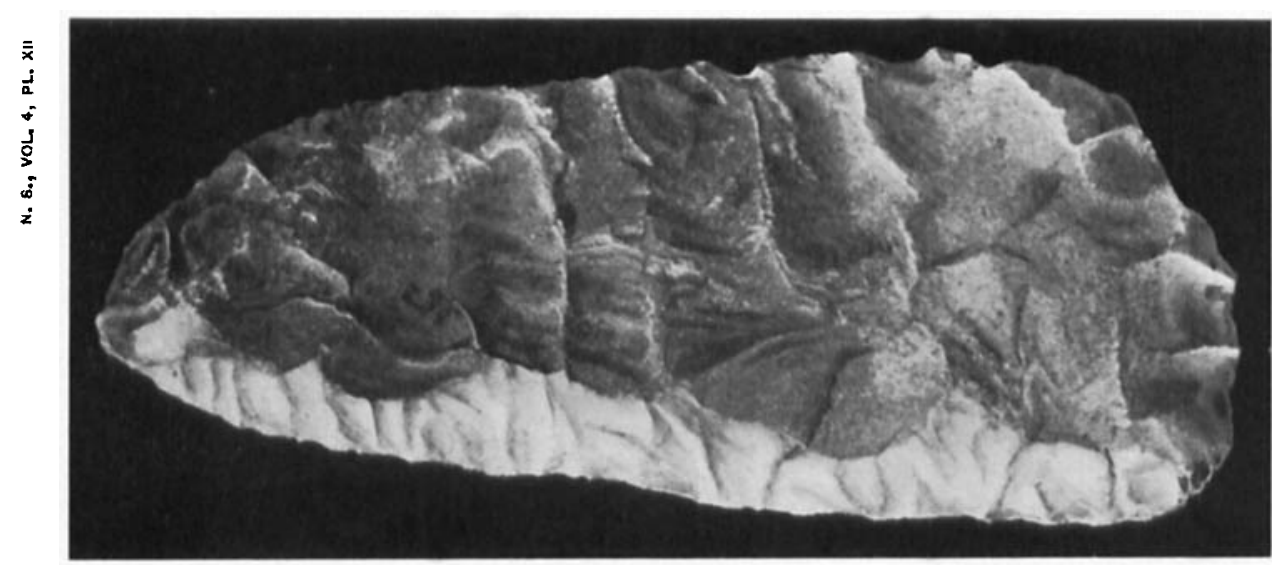

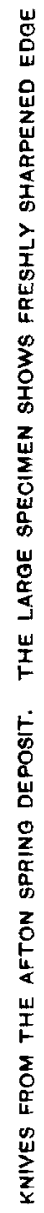

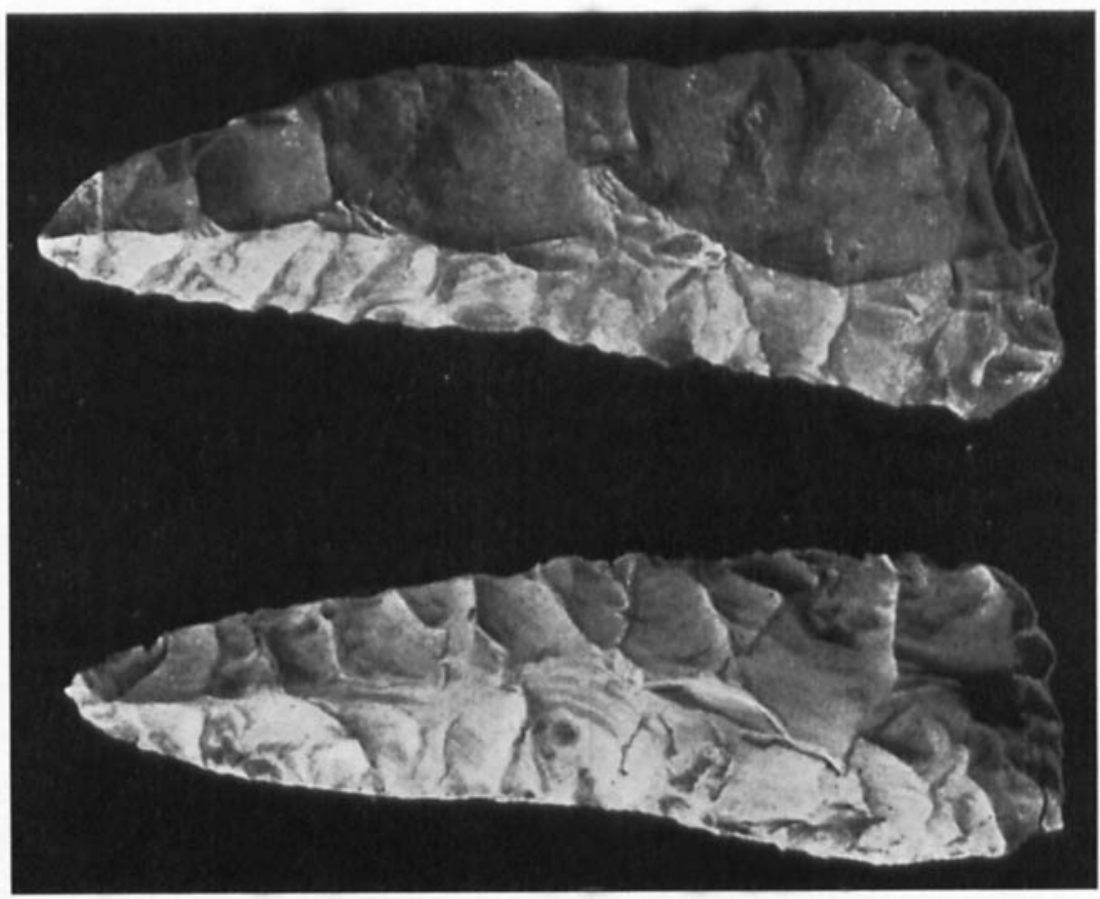


together in pairs inclosing the upper edge or back of the knife blade and lashed or cemented firmly in place. In two or three cases pairs were found so nearly matching in size and curvature as to have been successfully employed in this way. It is to be noted that these objects are very like implements used in some regions for pressure-flaking in the final trimming and sharpening of flint implements. Such implements would naturally form a part of the set of tools carried by a hunter of the Stone Age when about to set out on a prolonged expedition.

Among the many partially decayed objects of bone there were specimens resembling awls. The larger are made of the lower legbone of deer or antelope, and the smaller of the leg-bone of some large bird - a heron or sand-hill crane. Such utensils were an essential feature of the outfit of the lodge-dweller of the Great Plains, whose clothing and dwellings were necessarily made of skins sewn together.

\section{SIGNIFICANCE OF THE DEPOSIT}

As already indicated, the conclusion was reached at the outset that the casting of implements into the spring was not a caching or hiding of these precious objects, much less an idle, meaningless act. Stone implements were the most important possessions of the hunting tribes. Stone was their iron and steel. A vast amount of labor was expended in digging it from its bed in the hills and in reducing it to the forms desired, a work necessarily performed by men possessing great skill. The placing of these articles in the spring must, therefore, have been an act of great importance to the people concerned, and was doubtless in response to the demands of superstition. Water, and especially sources of water supply, have ever been regarded by primitive men, and even by some more advanced peoples, as dwelling places for spirit beings, and when sacrifices were believed to be necessary, the most precious possessions were cast in and no one was sufficiently bold to molest them. In fact, such a spot was generally regarded 
as sacred, and was avoided by all save those who were properly qualified to approach and make the offerings - the medicine-men or priests. One of the most striking facts connected with the Afton spring is that, although tradition indicates that it was a great gathering place for the native tribes, no traces of camping or dwelling were found in the vicinity.

That sacrifice to spirit occupants of springs was a widespread practice among the tribes of the west is clear, although observations of the fact are somewhat rare. Dr J. Owen Dorsey tells us that the Dakotas believe the buffalo to be of subterranean origin and refers to a tradition which asserts that one day when a principal man of one of the tribes was fasting and praying to the Sun-god, he saw the ghost of a buffalo rising from a spring. The Sioux have also water-gods and mystic beings associated with bogs.

In a recent publication by $\operatorname{Dr} A$. S. Gatschet, reference is made to a sacred spring or well of the Omaha, located in western Kansas, as follows :

"This curious water receptacle is situated on the top of a hill, and has a nearly circular form with about thirty feet diameter. All the hunting tribes of the prairie regard it with a religious interest mixed with awe; the Pani called it, or call it still, Kitch-Walushti; the Omahas, $N i$-wa $\chi u b e$, both names signifying sacred water. The miraculous quality of this pool, which chiefly astonishes the Indian mind, consists in a slow rising of the water whenever a large number of people stand around the brink. The water of the pool is perfectly limpid and considered to be bottomless; it harbors an aquatic monster which engulfs all the objects thrown into it, and never sends them up again. Indians offer to it beads, arrows, kerchiefs, earrings, even blankets, and all sink down immediately. Before putting clay or paint on their faces, the Indians impregnated these substances with the water of the well. They never drink of this water, but to allay their thirst they go to the neighboring Solomon river. Before buffalo hunting became a thing of the past, large hunting parties of natives often gathered around this pond source, and the following narrative circulated among them as

' Dorsey, J. Owen, Eleventh Annual Report of the Bureau of Ethnology, p. 538. 
a truthful report of what really occurred: Two Panis once returned with their horses. Having dismounted near the sacred water, one of the men stepped upon a turtle of the large species frequently found in the vicinity, about three feet long. The man's feet stuck to the turtle; he could not disengage himself from its treacherous shell, and when the turtle ran with his charge into the pool, the Indian was soon beyond possible rescue. His stupefied companion had seen the occurrence and went home to tell the tale."

\section{PEOPLES CONCERNED IN THE DEPOSIT}

The Afton region was occupied by tribes of Siouan stock, and particularly by the Osage who, in historic times, overran Neosho valley and neighboring districts. That it was some of these people who cast the offerings into the spring seems highly probable from the fact that the whole group of artifacts was just such as they would have used before the introduction of iron, and facts brought out by correspondence with the Indian agent for the Osage tribe make it certain that they alone were largely, if not wholly, responsible for the deposit.

The following paragraph is quoted from a letter from $\mathrm{Mr}$ O. A. Mitscher, Indian agent at Pawhuska, to Dr R. H. Harper of Afton, who had written making inquiries:

"SIR: Referring to your letter of the 7 th inst. relative to a certain spring located between Afton and Miami, in which were found numerous large teeth, about five hundred arrowpoints or spearheads, etc., and asking me to learn from the Osage Indians what, if anything, these signified, I have the honor to report that I submitted this matter to old man Red Eagle, the oldest man in the Osage tribe, who distinctly remembers the spring and states that it used to be the meeting place of the old medicine-men of the tribe when he was a young man; that the spring was held as a sacred place, and the doctors met there to hold their councils.

"The arrowpoints or spearheads were worn by the medicine-men as medals. It was the custorn of the tribe to offer the spearheads and other tokens to appease nature or their gods by depositing them in the spring, which they considered holy ground. This custom was observed whenever the tribe went on the war-path, to insure victory; when a

\footnotetext{
'Gatschet, A. S., in Fournal of American Folk-Lore, vol. II, no. Iv.
} 
child was born, to secure blessings for the child; and for any unusual undertaking, to make it successful. These deposits of tokens in the springs were also good-luck offerings.

"The spring was usually a shrine resorted to by the old-time Indians to commune with the unseen world. This custom, however, is not now in vogue, and has not been practiced by the Indians for some time.

"I am assured by Red Eagle that when he was a god, and before the white people intermingled with the Indians, it was the practice of the medicine-men and the leaders to gather at these springs for the purpose of holding councils, etc."

Some of the tribes farther west seem to have had similar practices, and instances of sacrifice to springs are recorded. $\mathrm{Mr}$ F. H. Cushing and Dr Walter Hough report the ceremonial use of springs in various localities, and Mr Thomas Ewbank speaks of a sacred spring near Zufii, New Mexico, as follows :

"The spring is cleared out every year, when an offering is made to the spirit of the font, of one or more water-pots, which are placed on the wall. A dozen or more whole ones were observed, while fragments abounded. Some of the remaining vases are reputed to have been offered centuries ago by the pueblo caciques. Specimens were brought away, notwithstanding the tradition that whoever abstracted one would be struck by lightning. As the Zuñ Indians do not have recourse to artificial irrigation, they depend entirely on rain; and it is their belief that, if they neglected the annual ceremonies at the spring, their crops would be destroyed by drought." 1

Early in I893 some Navaho Indians brought to $\mathrm{Mr} \mathrm{T}$. V. Keam, the trader at Keam's Cafron, in northeastern Arizona, several specimens of antique pottery which they had uncov. ered while digging for water at a point about five miles south of the trading-post. Mr Keam had the Indians continue the work, with the result that in the course of a week's digging they unearthed several hundred specimens of ancient pottery. $\mathrm{Mr}$ James Mooney, of the Bureau of American Ethnology, published the following statement relating to these finds:

1 Ewbank, "Report on Indian Tribes," Pacific Railroad Surveys, IlI, 1853-54 p. 44 . 
"On Sunday, February I 2, in company with Mr Keam, I rode over to the spot where the discovery had been made. It is in a rincon or side canyon, walled in by steep cliffs perhaps 150 feet in height. Toward the south the canyon opens out into an extensive valley [Jedito valley] occupied by several families of Navajos with their herds of sheep and goats. At the north end of the canyon several springs ooze up through the rocks and sand drifts, and it was in excavating one of these that the discovery was made. Several springs have now been dug out, but pottery has been found only at one. On climbing the steep ascent to the top of the mesa we find the remains of the ancient pueblo overlooking the valley on the east. It must have been an extensive settlement in its day, as large as any of the existing Hopi villages, as the ruins cover an area of perhaps four acres, and the whole neighborhood is strewn with fragments of stamped and painted pottery and flakes of flint and obsidian. The foundations of the walls are still well preserved, so that the outlines of the room can be distinctly traced, and by digging out the accumulated sand and débris it is probable that nearly the whole ground-plan might be restored. At the foot of the cliff, toward the south, traces of burnt clay and charcoal show where the pottery was made, and the steps cut into the rock by which the ancient inhabitants descended to the spring are still plainly visible.

"Several of the Indians were at work digging while we were there. They had excavated the principal spring, where the pottery had been found, down to bed clay, and had thrown the loosened sand out at the top. The instruments used were their hands and two long-handled shovels. The ground all around was strewn with fragments of pottery thrown out, and numerous other fragments were imbedded in the sand. It was evident that probably half the original number, including the largest specimens, had been destroyed in the digging process. By working in from the side, instead of from above, and proceeding carefully to remove the sand with the hands and some such small tool as a knife or a stick, probably three hundred or more pieces might have been taken out intact. Most of those preserved were small, finely decorated with designs in black and reddish brown, and of most unique shapes.

" . . . According to the statement given to $\mathrm{Mr}$ Keam by the Hopi, who have occupied this region from time immemorial, the ruined pueblo, which they call Kawaika, was formerly occupied by the Indians now in Laguna pueblo, west of the Rio Grande. They state also that their ancestors used to deposit jars and bowls near springs as votive offerings to the water gods. This would account for the fact that the 
vessels were all found close together at the principal spring, and appear from their size and shape to have been intended for religious rather than practical purposes. The custom of making offerings at springs to the water deities is common to all primitive tribes, and among the Arapahos and Cheyennes I have myself seen shawls and strips of calico hung up as sacrifices upon the bushes about every little watering-place in the vicinity of a regular camp."

Recent correspondence with Mr A. R. Graham, of Ferro, New Mexico, has brought to my attention the discovery of an offering spring at Hudson, New Mexico, and the following interesting paragraphs are quoted from his letter of January 18,1902 :

"The Hudson Hot spring (now called Faywood), is situated at the foot of a mesa four miles west of the Rio Mimbres - twenty-five miles due east of Silver City, this county, and about the same distance from Deming, N. M. It is directly on the old California highway, called the Sante Fé trail, and was used for many years - prior to the coming of the railroad in 1884 - as a stage station, being the first station west of Cook's Peak cañon, famous for its numerous hold-ups and Indian massacres in the early days.

"The very highly medicinal virtues of the waters were first discovered by Richard Hudson while serving as colonel of California volunteers in 1863 . He located at the spring after being mustered out, and held possession until $\mathrm{r} 894$, when I purchased the property. The flow from the spring then came from a cistern-shaped hole in the center of a round-top mound, elevated about thirty feet above the average surface surrounding the mound.

"The regular flow of the spring is five thousand gallons per hour, and never, to my knowledge, varies from this. I purchased the property for the purpose of establishing a health resort - the analysis showing the water to be unexcelled for the cure of rheumatism and stomach disorders. I built a large hotel at the east foot of the spring mound, and in order to utilize the hot water for bath-house and hotel use - including heating of the hotel through radiators - it was necessary for me to clean out the spring and wall it up to prevent loss throngh various small leaks through the mound formation. It proved a costly task, but I felt remunerated by the discoveries. The natural size of the spring excavation was twenty-five feet in diameter, and when I reached the depth of twenty-six feet I found the spring enclosed by

'James Mooney in American Anthropologist, July, I893, p. 283. 
a wall of "red marlite stone," round and symmetrical as man could build. Thousands of tons of dirt and rock had been thrown into the spring, and after removing this to the depth of twenty-six feet, I began to find Indian remains and relics of Indian art. The mound, twentysix feet in height, formed on top of the "red marlite" formation, had been made from the deposit of minerals in the water.

"At a depth of twenty-eight feet we discovered a distinct burial of a human being covered with mesquite bush, on top of which were bowlders. There were three such burials - or the remains of human beings - discovered between the twenty-eighth or thirty-first foot levels, and with each one were found war-clubs of stone, spearpoints, arrowheads, one wooden bow, almost complete, beads, mortars, etc.

"We secured quite well preserved parts of several skulls and other parts which would indicate that the people were of average stature. I supervised the whole work, and, with the assistance of my wife, now have nicely preserved and arranged, in a cabinet, every relic taken from the spring. The principal relics being: I, Parts of skulls and bones of several human beings. 2, Over fifty spearheads and arrowheads of every shape and style of workmanship, the spearheads being valuable for size and symmetry. 3, Nine large war-clubs, made of stone. 4, A large variety of teeth of animals, as well as large bones of extinct animals. 5, The most interesting relics are ten stone pipes, from four to seven inches in length. 6, Flint hatchet and a stone hammer, together with stones worn flat from use, beads made from vegetable seed and bird bones; part of two Indian bows, with which was found a quiver, in which was quite a bunch of long, coarse black hair that was soon lost after being dried.

"In the vicinity of Hudson Springs, within three to eight miles, there are numerous burying grounds and other evidences of dwellings of the earlier Indian tribes - the graves all containing more or less decorated pottery, a few good samples of which I also have.

"Within one mile of this hot spring are two cold springs, while one and one-half miles to the west is another warm spring of medicinal water (temperature $98^{\circ}$ ) that flows nearly one million gallons daily. This spring comes up from the south base of stone fortifications of considerable extent, the elevation standing out on a level mesa in a commanding position."

In the East, instances of the discovery of relics of arts in springs are rare. A deposit of flint blades found in a spring in North Carolina is exhibited in the Smithsonian Institution. 
The most notable examples of sacrifices of this general class are recorded by explorers of Central and South America, where offerings of gold and precious things of various kinds were cast into lakes, streams, springs, and the deep cenotes, or natural wells, to appease the gods believed to dwell therein.

Perhaps the most important fact connected with the finds at Afton is that we have here for the first time a large assortment of stone implements and other objects identified fully with a particular tribe and period. We have, as it were, recovered a notable chapter directly out of the prehistory of the primitive buffalo-hunting tribes of the Great Plains.

A second point of exceptional interest is that the deposit represents the offerings of a known tribe to the spirit beings with which the native conjurers had peopled a spring.

A third advantage of these over other deposits or caches of implements in the general region is that the exact motives of the makers of the offerings are made known to us. The story of the old Osage medicine-man conforms in every respect with the ideas formed by ethnologists through studies in other regions and among distinct peoples.

The association of human relics with the remains of extinct animals is always a matter of much scientific interest, but it appears that in this case the association has little significance, the fossil bones belonging in the original geological formations of the region, while the human relics are of recent introduction into the spring.

The course of events witnessed by these sulphur springs on the plains of the Neosho may be outlined somewhat as follows: About the close of Pliocene times, or in the earlier part of the Pleistocene, the great plains of the interior of the continent were overrun by vast herds of elephants, horses, bison, and other strange creatures, which slaked their thirst at the bubbling springs, if they existed, or otherwise in the streams and lakes of that time, 
leaving their carcases to rot there. Then the Ice Age supervened, and vast changes came over the region and the life thereof. The glacial chill drove the herds to the south or destroyed them, and the glacial floods buried their remains in deposits of sand and gravel. Then there arrived, from no one knows where, the buffalo, the elk, and the deer, with attendant swarms of carnivora and minor beasts. With these, or following them, came the Indian, with spear and bow and arrow, and the era of the chase began. Afton springs were still flowing and the beds of muck received the bodies of the dying herds as before. But man introduced a new element : the springs, abounding in bones of unknown monsters, became places of veneration and were peopled with spirits of the savage pantheon, and to these sacrifices were made, the most precious possessions finding a resting place in the sulphurous shrine. The last, the present, episode in Afton's history, witnessed the disappearance of the buffalo and the Red Man, and the coming of new cattle, a new horse, and a strange people. Then follow the keeping of herds on the plains about, the building of towns, the construction of the railway, and finally the cleaning out of the springs and the discovery of its interesting treasures.

AM. ANTH. N. S., 4-9. 